OPEN ACCESS

Edited by: Ana E. Escalante,

National Autonomous University of Mexico, Mexico

Reviewed by:

Esperanza Martinez-Romero, National Autonomous University of Mexico, Mexico Julie Ardley,

Murdoch University, Australia

${ }^{*}$ Correspondence: Xavier Perre xavier.perret@unige.ch

Specialty section: This article was submitted to Microbial Symbioses, a section of the journal Frontiers in Microbiology

Received: 19 October 2018 Accepted: 22 January 2019 Published: 13 February 2019

Citation:

Cherni AE and Perret X (2019) Deletion of rRNA Operons of Sinorhizobium fredii Strain NGR234 and Impact on Symbiosis With

Legumes. Front. Microbiol. 10:154 doi: 10.3389/fmicb.2019.00154

\section{Deletion of rRNA Operons of Sinorhizobium fredii Strain NGR234 and Impact on Symbiosis With Legumes}

\author{
Ala Eddine Cherni and Xavier Perret* \\ Microbiology Unit, Department of Botany and Plant Biology, Sciences III, University of Geneva, Geneva, Switzerland
}

During their lifecycle, from free-living soil bacteria to endosymbiotic nitrogen-fixing bacteroids of legumes, rhizobia must colonize, and cope with environments where nutrient concentrations and compositions vary greatly. Bacterial colonization of legume rhizospheres and of root surfaces is subject to a fierce competition for plant exudates. By contrast root nodules offer to rhizobia sheltered nutrient-rich environments within which the cells that successfully propagated via infection threads can rapidly multiply. To explore the effects on symbiosis of a slower rhizobia growth and metabolism, we deleted one or two copies of the three functional rRNA operons of the promiscuous Sinorhizobium fredii strain NGR234 and examined the impact of these mutations on free-living and symbiotic lifestyles. Strains with two functional rRNA operons (NGR $\Delta r R N A 1$ and NGR $\Delta r R N A 3$ ) grew almost as rapidly as NGR234, and NGR $\Delta$ rRNA1 was as proficient as the parent strain on all of the five legume species tested. By contrast, the NGR $\Delta r R N A 1,3$ double mutant, which carried a single rRNA operon and grew significantly slower than NGR234, had a reduced symbiotic proficiency on Cajanus cajan, Macroptilium atropurpureum, Tephrosia vogelii, and Vigna unguiculata. In addition, while NGR $\Delta$ rRNA1 and NGR234 equally competed for nodulation of $V$. unguiculata, strain NGR $\Delta \mathrm{rRNA1,3}$ was clearly outcompeted by wild-type. Surprisingly, on Leucaena leucocephala, NGR $\Delta r R N A 1,3$ was the most proficient strain and competed equally NGR234 for nodule occupation. Together, these results indicate that for strains with otherwise identical repertoires of symbiotic genes, a faster growth on roots and/or inside plant tissues may contribute to secure access to nodules of some hosts. By contrast, other legumes such as L. leucocephala appear as less selective and capable of providing symbiotic environments susceptible to accommodate strains with a broader spectrum of competences.

Keywords: nitrogen fixation, nodulation, competition, rhizosphere, colonization

\section{INTRODUCTION}

Nitrogen-fixing symbioses between legumes and soil bacteria, commonly known as rhizobia, are responsible for introducing a large fraction of fixed $\mathrm{N}$ into terrestrial ecosystems. These beneficial plant-microbe associations come in many forms and shapes (Masson-Boivin et al., 2009; Sprent et al., 2013), yet all involve the intracellular colonization by soil rhizobia of legume cells grouped 
into nodules: Specialized root (or more rarely stem) organs within which endosymbiotic rhizobia reduce atmospheric nitrogen $\left(\mathrm{N}_{2}\right)$. Although alternative mechanisms exist in diverse legume species, infection of root tissues is often mediated by infection threads (ITs) that guide dividing rhizobia through several cortical cell layers and toward the developing nodule primordia (Gage, 2004). In most legume crops, establishment of symbiosis is triggered and coordinated by molecular signals exchanged between legumes and rhizobia, beginning with the secretion of plant flavonoids to which compatible rhizobia respond with the synthesis and secretion of nodulation (Nod-) factors (NF). In turn, NF provoke the curling of root hairs onto which rhizobia are attached, the division of cortical cells that will eventually form nodule primordia, and permit the entry of rhizobia into root hairs (Perret et al., 2000; Oldroyd et al., 2011).

In Medicago truncatula, initiation of ITs begins once root hairs are fully curled and have entrapped, in most cases, a single rhizobia cell at the origin of an enclosed micro-colony. ITs begin to form $10-20 \mathrm{~h}$ after infection chambers are sealed (Fournier et al., 2015), and extend by $4-5 \mu \mathrm{m}$ per hour with alternating phases of rapid or slower elongation depending on the intracellular dynamics of infected root hairs (Fournier et al., 2008). Successive cell divisions allow rhizobia to progress within developing ITs and microscopy studies showed that generation time of rhizobia within ITs was close to that observed in vitro using standard growth media (Gage, 2002). Thus, growth conditions within developing ITs must be favorable to rhizobia with enough nutrients to sustain a rapid bacterial division when needed. It is unknown whether some legumes, at one stage of the infection process, favor strains with either faster or slower generation times, however. In any event, bacterial surface components and secreted proteins play important roles in modulating the infection process (Jones et al., 2007). Once released from ITs, rhizobia multiply within the cytoplasm of nodule cells and eventually differentiate into $\mathrm{N}_{2}$-fixing bacteroids. Reduced nitrogen is assimilated by host plants in exchange for amino acids and carbon sources derived from photosynthesis that fuel the intense bacteroid metabolism (Poole et al., 2018).

Nodule morphology and characteristics vary considerably between legume species (Sprent et al., 2017). Major legume crops make either one of two nodule types that can be distinguished according to their ontogeny and development, however (Ferguson et al., 2010). Nodules of indeterminate growth possess a persistent distal meristem that, in Medicago species, derives from middle cortical cells with inner cortical and pericycle cells also contributing to nodule growth (Xiao et al., 2014). Mature indeterminate nodules (IDN) are elongated and characterized by a longitudinal gradient of plant and rhizobia cells at different stages of differentiation. Inside IDN of $M$. truncatula and other legumes of the Inverted Repeat-Lacking Clade (IRLC) (Montiel et al., 2017), nodule-specific cysteine-rich plant peptides provoke a profound and irreversible differentiation of bacteroids making them incapable of resuming free-living growth (Mergaert et al., 2006). Yet, inside IDN of the non-galegoid species Mimosa pudica (mimosoid clade of Caesalpinioideae), bacteroids were reported to resemble free-living cells in many aspects indicating that terminal bacteroid differentiation was not a general feature of IDN making legumes (Marchetti et al., 2011). By contrast, determinate nodules (DN) are spherical in shape, and reported to originate with external cortical cells and to have a transient meristematic activity, resulting in a differentiation of plant and rhizobia cells that is more synchronous throughout the nodule. As bacteroids of DN are not terminally differentiated, most rhizobia can resume a free-living growth in soils once nodules senesce and disaggregate. Recently, plants of the Indigofera and Tephrosia genera that were initially thought to form IDN, were reported to make nodules that carry secondary clusters of dividing cells instead of a persistent meristem (Ren, 2018). Yet, regardless of the strain or type of nodule considered, rhizobia must first efficiently colonize the plant rhizosphere, multiply within growing ITs, circumvent or withstand plant defenses, colonize and establish persistent colonies inside nodules cells, before becoming proficient symbionts. As a single rhizobia cell suffices to make a functional nodule containing up to $10^{8}$ to $10^{9}$ bacteroids (Kiers et al., 2003), numerous cell divisions and intense bacterial metabolism are needed to secure establishment of a proficient symbiosis.

Amongst the many rhizobia strains studied worldwide, Sinorhizobium (Ensifer) fredii strain NGR234 has the broadest host-range described so far (Pueppke and Broughton, 1999). Capable of nodulating plants of $>120$ legume genera, NGR234 fixes nitrogen inside nodules of determinate and indeterminate types. Such unsurpassed symbiotic promiscuity, raised the question of the molecular mechanisms used by NGR234 to elicit root nodule formation, successfully infect nodule cells and fix nitrogen on/in so many hosts (Broughton et al., 2000; Perret et al., 2003). Many studies confirmed that the $536 \mathrm{~kb}$ plasmid called pNGR234a carries most of the symbiotic genes [including (Broughton et al., 1986; Perret et al., 1991; Freiberg et al., 1997)], albeit the NGR234 3.9 $\mathrm{Mb}$ chromosome and 2.4 $\mathrm{Mb}$ megaplasmid pNGR234b were also shown to contribute to symbiosis (Viprey et al., 2000; Schmeisser et al., 2009). Strain NGR234 is not necessarily the most infective or proficient microsymbiont, however. For example, the slower growing Bradyrhizobium japonicum strain G49 outcompeted NGR234 on Vigna unguiculata (Ziegler et al., 2012), even though cowpea is considered a promiscuous legume (Lewin et al., 1987). Similarly, the slow-growing B. japonicum strain E109 also outcompeted the faster-growing $S$. fredii strain SMH12 on several soybean cultivars (Pastorino et al., 2015). Although many factors contribute to make strains more competitive than others for nodulation (Triplett and Sadowsky, 1992), a slower growth rate apparently does not reduce competitiveness of bradyrhizobia.

Fast-growing rhizobia (e.g., sinorhizobia, mesorhizobia, etc.) have generation times of $2-5 \mathrm{~h}$, whereas slower growing strains such as bradyrhizobia may divide every 6-13 h (Keyser et al., 1982). Various genetic and environmental factors influence growth rates, yet bacteria with fewer ribosomal RNA (rRNA) 
operons tend to grow slower than those with many rRNA gene copies (Shrestha et al., 2007), with the number of rRNA operons ranging from 1 to 15 copies per genome (Klappenbach et al., 2001). In general, rRNA operons code for 5S, 16S, and 23S rRNA subunits and one or several tRNA genes. NGR234 has three such rRNA operons (Perret et al., 1991), and was shown to divide every $2.5 \mathrm{~h}$ on a minimal medium supplemented with succinate as a sole carbon source (Saroso et al., 1984). Some rhizobia have more than three rRNA operon copies, including the fast growing strains Cupriavidus taiwanensis LMG19424 $4^{\mathrm{T}}$ (two chromosomes and 5 rRNA operons) (Amadou et al., 2008), Methylobacterium nodulans ORS2060 ${ }^{\mathrm{T}}$ (one chromosome and 7 rRNA operons) (Marx et al., 2012) and Paraburkholderia phymatum strain STM815 ${ }^{\mathrm{T}}$ (two chromosomes and 6 rRNA operons) (Moulin et al., 2014), which take two to three days to form visible colonies on synthetic media. By contrast, a single rRNA operon containing strain such as Bradyrhizobium diazoefficiens USDA $110^{\mathrm{T}}$ divides every $9.6 \mathrm{~h}$ (Keyser et al., 1982), while the extremely slow-growing Bradyrhizobium liaoningense isolates have generation times of up to $40 \mathrm{~h}$ (Xu et al., 1995). Studies on Escherichia coli showed that cells with deletions in one to two of the seven rRNA operon copies present in this species could grow at nearly maximal rate and remained viable even with as little as a single rRNA operon (Asai et al., 1999; Bollenbach et al., 2009). Yet, in competition experiments wild-type cells rapidly outgrew mutants deleted for one or two rRNA operons, indicating that the seven operons architecture was favored to secure a rapid adaptation to "feast and famine" conditions encountered by E. coli through its life-history (Stevenson and Schmidt, 2004). Experiments on Bacillus subtilis confirmed that mutants with only one out of ten rRNA operons grew poorly but nonetheless retained the ability to sporulate, albeit at lower frequencies than the wild type (Nanamiya et al., 2010). While these findings confirmed that bacteria remained viable even with a number of rRNA operons considerably reduced, complex cell processes (such as division and sporulation) were affected making rRNA-mutants less fit than parent strains.

Changes in nutrient availability have been shown to shape bacterial communities, with strains having fewer rRNA operons dominating older successional communities with scarcer resources (Nemergut et al., 2016), and with rRNA operon numbers becoming predictors of bacterial reproductive strategies (Roller et al., 2016). During their lifecycle, rhizobia must operate and compete in environments where resources and cell densities vary greatly, including in nutrient poor and thinly populated soils, rich but highly colonized root surfaces, to the particularly sheltered nutrient-abundant but highly specialized nodule cells. Given these markedly different environments within which rhizobia must operate, either as free-living or as endosymbiotic cells, we asked whether deletion of rRNA operons would significantly alter symbiotic proficiency of a promiscuous rhizobia strain. Accordingly, NGR234 was deleted of one and two of its three functional copies of rRNA operons and the effects of these deletions on growth, nodulation of several legume species, symbiotic nitrogen fixation and competition for nodulation were examined.

\section{MATERIALS AND METHODS}

\section{Microbiological Techniques}

Plasmids and bacterial strains used in this study are described in Supplementary Table S1. NGR234 and derivative strains were grown at $27^{\circ} \mathrm{C}$ in/on rhizobia minimal medium supplemented with succinate (RMS) (Broughton et al., 1986) or tryptone yeast (TY) medium (Beringer, 1974). E. coli was grown at $37^{\circ} \mathrm{C}$ in/on LB. Antibiotics kanamycin, rifampicin, and spectinomycin were used at final concentrations of $50 \mu \mathrm{g} \mathrm{ml}^{-1}$. To compare growth of NGR234 and derivative mutants, $10^{8}$ cells from overnight pre-cultures at $\mathrm{OD}_{600}$ comprised between 0.3 and 0.5 were transferred to $50 \mathrm{ml}$ fresh RMS cultures that were incubated for 3 days at $27^{\circ} \mathrm{C}$ and $190 \mathrm{rpm}$. For each strain, three replicate cultures were followed in parallel and $\mathrm{OD}_{600}$ was measured at regular intervals. Generation time was estimated during the exponential phase of growth, using as standard the NGR234 growth curve established by Broughton and Fellay (unpublished). Development of colonies formed by NGR234 and rRNA-deleted mutants was followed on TY and RMS plates using serial cell dilutions to obtain plates with ca. 10, 100, and 1000 colonies. After 5 and 7 days of incubation at $27^{\circ} \mathrm{C}$ for TY and RMS, respectively, the diameter of at least 30 isolated colonies per strain was measured using the Fiji image processing software (Schindelin et al., 2012).

\section{Sequence Verification and Deletion of the NGR234 rRNA Operons}

To confirm sequence polymorphisms in promoter and terminator regions as well as in the 16S rRNA genes, overlapping clones of an ordered cosmid library (Perret et al., 1991) were used as templates to amplify each of the three rRNA operons independently: pXB123 and pXB487 were selected for amplifying the rRNA1 operon, pXB375 and pXB684 covered the rRNA2 locus, pXB72 and pXB942 carried the rRNA3 operon. End sequences of the inserts carried by these cosmids were obtained during the sequencing of the NGR234 genome (Schmeisser et al., 2009), allowing for a precise mapping onto the chromosome replicon (see Supplementary Table S1). Promoter and terminator regions were amplified and sequenced using combinations of primers listed in Supplementary Table S2 and which positions are shown in Figure 1. 16S rRNA genes were amplified and sequenced using the 16S-For3 and 16S-Rev3 primers (Fossou et al., 2016). To obtain the NGR $\Delta$ rRNA3 mutant, regions flanking the rRNA3 operon were amplified using C3D-For/C3D-Rev and C3G-For/C3G-Rev primers (Supplementary Table S2) and NGR234 genomic DNA as template. The C3G-For/C3G-Rev and C3D-For/C3D-Rev amplicons were restricted by, respectively, SpeI and BamHI or XhoI and BamHI, and the resulting 1,391 and 979 bp fragments cloned into pBluescript $\mathrm{KS}+$ (Stratagene) restricted by SpeI and XhoI, yielding construct pBSC3. The spectinomycin 


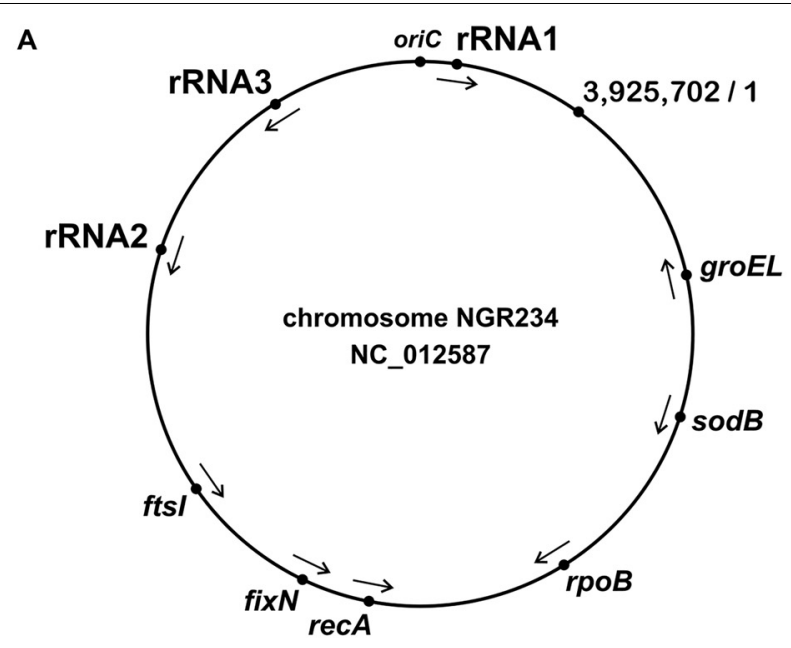

B
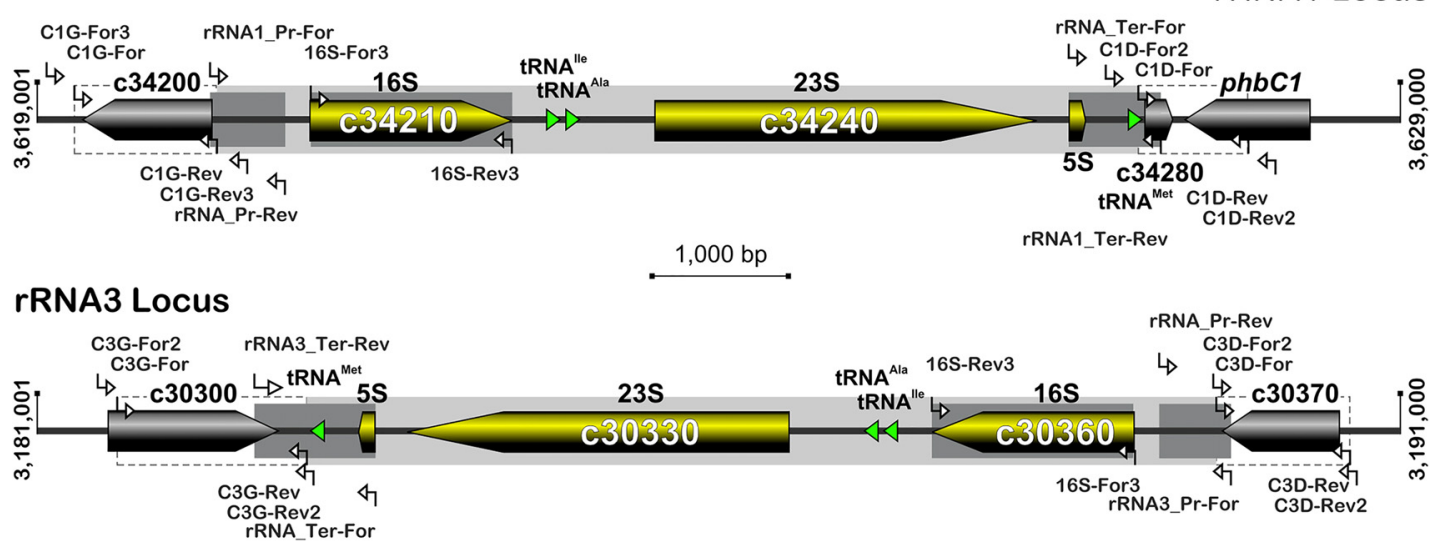

FIGURE 1 | Organization of rRNA operons on NGR234 chromosome and detailed genetic maps of the rRNA1 and rRNA3 loci. (A) Circular map of the 3.9 Mb chromosome of NGR234 with the positions and orientations of the three rRNA operons as reported in the accession number NC_012587 (Schmeisser et al., 2009 ). (B) Detailed genetic maps of the rRNA1 and rRNA3 operons: Genes coding for 5S, 16S, and 23S rRNA subunits are shown as yellow arrows oriented according to transcription, while genes predicted to code for proteins are shaded in gray and those for tRNAs depicted as green triangles. The section of each operon that was replaced by Omega is shaded in gray. Segments of the $16 \mathrm{~S}$ genes, promoters, and terminators that were verified by sequencing cosmid DNAs are highlighted in darker shades of gray. Regions flanking the deleted rRNA operons and used as sites for homologous recombination are delimited by dashed lines. Small and labeled white arrows represent the positions and orientations of primers used in this work.

resistant $\left(\mathrm{Sp}^{\mathrm{R}}\right) \Omega$ cassette of $\mathrm{pHP} 45$ (Prentki and Krisch, 1984) was cloned into the unique BamHI site of pBSC3 to generate pBSC3Sp, which $4.4 \mathrm{~kb}$ SpeI-XhoI insert was further subcloned into pJQ200SK (Quandt and Hynes, 1993). The resulting pJQC3Sp clone was then mobilized into NGR234 by triparental mating using pRK2013 as helper (Figurski and Helinski, 1979). Eventually, mutants with the rRNA3 operon replaced by the $\Omega\left(\mathrm{Sp}^{\mathrm{R}}\right)$ interposon were selected onto RMS plates containing spectinomycin $(50 \mu \mathrm{g} / \mathrm{ml})$ and $5 \%(\mathrm{w} / \mathrm{v})$ sucrose. Candidate colonies for marker exchange were purified and genotyped by PCR using combinations of primers matching sequences outside of (C3D-Rev2 and C3G-For2) or within the deleted rRNA3 operon (C3D-For2 and C3G-Rev2), as well as within the $\Omega$ cassette (primer Omega) (see Supplementary Table S2 and Figure 1). A similar strategy was used to delete the rRNA1 operon and yield the NGR $\Delta$ rRNA1 mutant, except that flanking sequences were amplified with the C1D-For/C1D-Rev and C1G-For/C1G-Rev primer pairs and were directly cloned into pJQ200SK using SpeI, BamHI, and PstI as restriction enzymes, yielding the pJQC1 intermediate construct (Supplementary Table S1). pJQC1Km was obtained by cloning the kanamycin resistant $\left(\mathrm{Km}^{\mathrm{R}}\right) \Omega$ cassette into the unique BamHI site of pJQC1. Following tri-parental mating and selection of candidate $\mathrm{Km}^{\mathrm{R}}$ NGR $\Delta$ rRNA1 mutants on sucrosecontaining media, deletion of the rRNA1 operon was confirmed by PCR using combinations of the following primers: C1D-Rev2, C1G-For3, C1D-For2, C1G-Rev3, and Omega. Inserts cloned into pBSC3 and pJQC1 were verified by DNA sequencing. The mutant of NGR234 lacking both rRNA1 and rRNA3 operons (strain NGR $\Delta$ rRNA1,3) was obtained by deleting the rRNA1 copy in the selected NGR $\Delta$ rRNA3 mutant, using a similar procedure as described above. Genotype of NGR $\Delta$ rRNA1,3 
candidate mutants was verified by PCR, using primer sets designed to confirm deletion of the rRNA1 copy.

\section{Plant Assays}

Nodulation assays were conducted as in Fumeaux et al. (2011), with plants of Cajanus cajan, Leucaena leucocephala, Macroptilium atropurpureum cv. Siratro, Tephrosia vogelii, and V. unguiculata cv. Red Caloona grown in Magenta jars containing vermiculite and watered using nitrogen-free $B \& D$ solution (Broughton and Dilworth, 1971). Seeds were surface-sterilized and incubated for 2-3 days in the dark, at $27^{\circ} \mathrm{C}$ and on $\mathrm{B} \& \mathrm{D}$ agar plates to germinate. Once germinated, seedlings were transferred to Magenta jars, two plants per pot, and each plantlet was inoculated 3 days later with a $200 \mu$ l water suspension of $2 \times 10^{8}$ freshly grown rhizobia. Plants were grown in controlled conditions with a light phase of $12 \mathrm{~h}$, a day temperature of $27^{\circ} \mathrm{C}$, a night temperature of $20^{\circ} \mathrm{C}$ and in $60-70 \%$ humidity. At the end of each assay, shoots were harvested and dried at $60^{\circ} \mathrm{C}$ for 2 days prior to being weighted. Root systems were cleared of vermiculite and all nodules collected, counted and weighted, and then stored at $-60^{\circ} \mathrm{C}$ until further use. Symbiotic proficiency of each strain was assessed by counting the total number of nodules, fresh weight of nodules and shoot dry weight of inoculated or control plants. To compare the kinetics of nodulation of NGR234 and rRNA-deletion mutants, $V$. unguiculata plants were grown as described above and harvested after 12, 24, and 36 days post-inoculation (dpi). At each time point, at least 12 plants were harvested for each treatment. In parallel, the relative chlorophyll content of first (between 12 and $21 \mathrm{dpi}$ ) and second (from 24 to $36 \mathrm{dpi}$ ) trifoliate leaves of $V$. unguiculata plants was monitored every third day using a Minolta SPAD-502 chlorophyll meter (Markwell and Blevins, 1999). For each inoculum, at least 8 plants in 4 pots were surveyed throughout the experiment with each time point corresponding to the mean of 48 measurements ( 2 readings per leaflet and 3 leaflets per plant). Trials to assess competition for nodule occupancy between inoculated strains were conducted as follows. Each L. leucocephala or V. unguiculata seedling was inoculated with a total of $10^{6}$ bacteria in a final volume of $200 \mu \mathrm{l}$. Appropriate amounts of single-strain inoculant were mixed to obtain final ratios of $1: 1,4: 1$, and 1:4 for NGR234 and NGR $\Delta$ rRNA1, while NGR234 and NGR $\Delta$ rRNA1,3 were only inoculated at 1:1 ratio. Respective titers of inoculated rhizobia were verified by plating aliquots of serial dilutions of each inoculum on TYA containing either rifampicin (all cells grew) or kanamycin (only mutants grew). To obtain nodules of sufficient size for subsequent analyses, plants of L. leucocephala and V. unguiculata were harvested at 28 and $24 \mathrm{dpi}$, respectively. Once harvested, root nodules were surface sterilized $3 \mathrm{~min}$ in $70 \% \mathrm{EtOH}$, washed three times in sterile $\mathrm{H}_{2} \mathrm{O}, 3 \mathrm{~min}$ in $4 \% \mathrm{NaClO}$, followed by six washes in sterile $\mathrm{H}_{2} \mathrm{O}$. Surface sterilized nodules were then processed separately inside sterile microtiter plates with U-shape wells and thoroughly crushed in $70 \mu \mathrm{l}$ of sterile distilled water. Nodule homogenates were replica-plated onto TY plates containing either rifampicin or kanamycin to identify nodules containing mutant strains. Growing colonies were examined after 6-8 days of growth at $27^{\circ} \mathrm{C}$, using $>140$ nodules collected on more than 10 plants for each of the treatments.

\section{RESULTS}

\section{Structure and Organization of the NGR234 rRNA Operons}

The rRNA operons flank both sides of the chromosomal replication origin with genes oriented as the replication forks (Figure 1A). All three rRNA operons have identical structures: One $16 \mathrm{~S}$ rRNA gene at the $5^{\prime}$-end, followed by tRNA ${ }^{\text {Ile }}$ and tRNA $^{\text {Ala }}$ copies, $23 \mathrm{~S}$ and 5S rRNA genes and, at the $3^{\prime}$-end of the operon a copy of tRNA ${ }^{\text {Met }}$ (Figure 1B). According to published genome data (Schmeisser et al., 2009), polymorphisms in the three rRNA operons occur mostly in the promoter and terminator regions, with the rRNA3 differing most from the rRNA1 and rRNA2 copies. All three rRNA promoters include conserved -10 and -35 boxes that are separated by spacer sequences, of which only the rRNA3 copy differs by 7 out of 18 bp (see Supplementary Figure S1). Upstream of the conserved -35 hexamers, all three promoters include A-T rich sequences characteristic of upstream (UP) elements known to interact with the RNA polymerase complex and enhance promoter activity (Ross et al., 1993). NGR234 rRNA promoters include putative box A-like anti-termination and box B-like sequences (Berg et al., 1989), the latter of which form processing stalks with inverted repeats found downstream the $16 \mathrm{~S}$ rRNA copies (Srivastava and Schlessinger, 1990). Terminator regions downstream of tRNA $^{\text {Met }}$ sequences include conserved stem-loop structures preceded by series of adenines and followed by stretches of thymidine residues, characteristic of rho-independent type of transcriptional terminators (Farnham and Platt, 1981). Likewise its promoter region, the rRNA3 terminator region differs significantly from those of the rRNA1 and rRNA2 operons, with as many as 4 gaps and 79 polymorphic positions including in between the 5S rRNA and tRNA ${ }^{\text {Met }}$ genes and within the GC-rich palindromic terminator sequence (see Supplementary Figure S2). According to Schmeisser et al. (2009), all copies of 5S (NGR_c26480, NGR_c30320, and NGR_c34260) and 23S (NGR_c26490, NGR_c30330, and NGR_c34240) rRNA genes were identical whereas 16S rDNA sequences (NGR_c26520, NGR_c30306, and NGR_c34210) differed at eight nucleotide positions. Compared to consensus the $16 \mathrm{~S}$ rRNA2 gene was reported to differ by one nucleotide while the $16 \mathrm{~S}$ rRNA3 copy carried seven mismatches (see Supplementary Figure S3). Although sequence variations between 16S rRNA copies are not unheard of (Coenye and Vandamme, 2003; Acinas et al., 2004), allelic variations reported for NGR234 were verified by using as templates for $16 \mathrm{~S}$ gene sequencing sets of overlapping cosmids that cover each of the three rRNA operons (Perret et al., 1991; Supplementary Table S1). Unexpectedly, sequencing data showed that copies of the $16 \mathrm{~S}$ rRNA genes carried by the six cosmids were identical (Supplementary Figure S3). Thus, except for genuine differences in the promoter and terminator regions of copy 3, all of which were confirmed by sequencing cosmid templates, the rRNA operons of NGR234 are otherwise identical. 


\section{Construction of rRNA-Deletion Mutants and Phenotypes on Free-Living Growth}

Because its promoter, $5 \mathrm{~S}$ rRNA and tRNA ${ }^{\text {Met }}$ intergenic as well as terminator regions differed most from the other two copies, the rRNA3 operon was deemed as less likely to be essential for cellular processes and thus, was selected as the first target for mutagenesis. Accordingly, the complete rRNA3 operon was replaced by a spectinomycin-resistant version of the omega interposon (Prentki and Krisch, 1984). Given the NGR $\Delta$ rRNA3 mutant was viable, the full rRNA1 operon was then selected as the second target for replacement by a kanamycin-resistant omega cassette. Eventually, after being deleted separately, the rRNA1 $\left(\mathrm{Km}^{\mathrm{R}}\right)$ and rRNA3 $\left(\mathrm{Sp}^{\mathrm{R}}\right)$ deletions were combined to yield the NGR $\triangle$ rRNA1,3 mutant with a single rRNA2 operon. Development of parent and rRNA-deleted mutants was compared on/in rich TY and minimal RMS synthetic growth media. To observe the effect of deleting rRNA operons on the formation and development of isolated colonies on solid media, serial dilutions of exponentially growing cultures were plated onto TY and RMS agar $(1.5 \% \mathrm{w} / \mathrm{v})$ and incubated for 5 and 7 days, respectively. On TY agar, the diameter of NGR234 colonies was of $2.6( \pm 0.7) \mathrm{mm}$ whereas NGR $\Delta$ rRNA1 and NGR $\triangle$ rRNA3 mutants formed colonies of $2.3( \pm 0.9)$ $\mathrm{mm}$ and $2.2( \pm 0.7) \mathrm{mm}$, respectively. By contrast, growth of NGR $\Delta$ rRNA1,3 was significantly slower, with colonies reaching diameters of only $1.2( \pm 0.4) \mathrm{mm}$ after 5 days of incubation (see Supplementary Figure S4). After 7 days on RMS agar, colonies of NGR234, NGR $\Delta$ rRNA1, NGR $\Delta$ rRNA3, and NGR $\Delta$ rRNA1,3 had diameters of $2.6( \pm 0.5), 2.4( \pm 0.5), 2.6( \pm 0.6)$, and 1.5 $( \pm 0.3) \mathrm{mm}$, respectively. These results indicated that deletion of either of the rRNA1 or rRNA3 operons had a modest but noticeable impact on NGR234 viability and cellular growth on synthetic media whereas growth of NGR $\Delta$ rRNA1,3 was considerably slower. Colony morphology remained unaltered, suggesting stability of mutated strains (Bollenbach et al., 2009). To better compare growth rates of the parent, NGR $\Delta$ rRNA1, NGR $\Delta$ rRNA3, and NGR $\Delta$ rRNA1,3 mutant strains, cells were grown in RMS liquid cultures at $27^{\circ} \mathrm{C}$ and optical density of cultures was monitored during three consecutive days (see Figure 2). Mutant strains deleted for one rRNA operon grew at similar rates but slower than NGR234, while doubling time of NGR $\triangle$ rRNA1,3 was, as expected, considerably extended. Based upon these measurements, generation time for each of the tested strains was estimated at $160( \pm 10) \mathrm{min}$ for NGR234, $185( \pm 14)$ min for NGR $\triangle$ rRNA3, $190( \pm 16)$ min for NGR $\Delta$ rRNA1, and as much as 245 ( $\pm 8 \mathrm{~min})$ for NGR $\Delta$ rRNA1,3.

\section{Effect of rRNA Deletion on Symbiosis With Legumes}

To test the effect of deleting rRNA operons on nodulation and nitrogen fixation, the symbiotic proficiency of NGR234, NGR $\triangle$ rRNA1, and NGR $\Delta$ rRNA1,3 was examined on five legume species that formed nodules of either determinate (M. atropurpureum and $V$. unguiculata), indeterminate (L. leucocephala) or determinate with secondary clusters of dividing cells (T. vogelii and by analogy $C$. cajan as well)

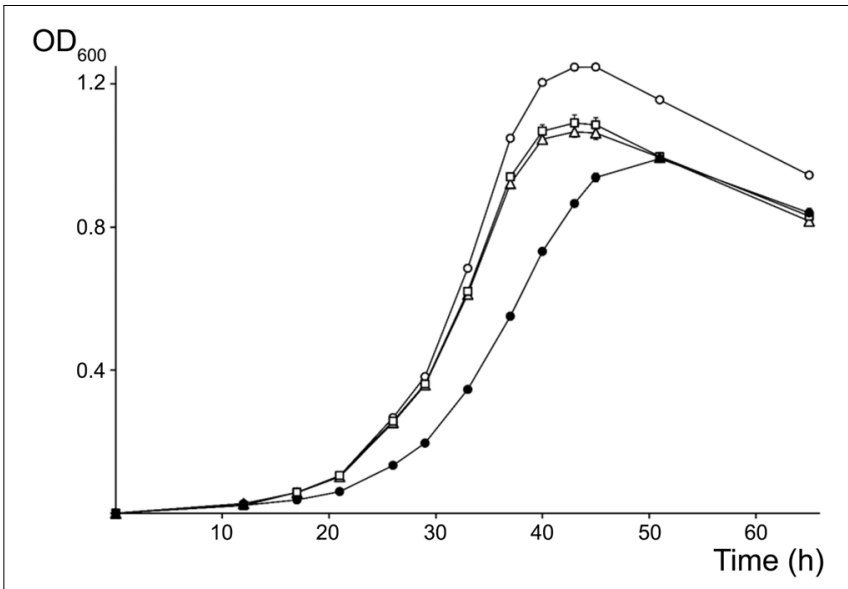

FIGURE 2 | Growth curves for NGR234 and the rRNA-deletion mutants. Evolution of the growth of NGR234 (O), NGR $\Delta r R N A 1(\Delta)$, NGR $\Delta r R N A 3(\square)$, and NGR $\triangle \mathrm{rRNA} 1,3(\mathbf{)})$ strains in liquid RMS cultures at $27^{\circ} \mathrm{C}$ and with orbital shaking. Error bars indicate the standard deviation of the mean, with three independent cultures grown in parallel for each strain.

types. Phenotype of each inoculum was examined using nodule number $(\mathrm{NN})$, total nodule fresh weight $(\mathrm{NFW})$, and shoot dry weight (SDW) of inoculated plants as markers for symbiotic activity. As shown in Table 1, both of the NGR $\triangle$ rRNA1 and NGR $\Delta$ rRNA1,3 mutants still formed nodules (Nod+ phenotype) and reduced atmospheric nitrogen (Fix + phenotype) on all of the hosts. SDW and NFW of plants inoculated with NGR $\triangle$ rRNA1 or NGR234 were similar and only the NN of NGR $\triangle$ rRNA1 showed a statistically significant decrease when inoculated onto $V$. unguiculata. By contrast, symbiotic proficiency of NGR $\triangle$ rRNA1,3 was impaired on four out of the five legume species tested with NN, NFW, and/or SDW being significantly reduced $(P<0.05)$ when compared to plants inoculated with NGR234. Interestingly, when L. leucocephala plants were harvested at $49 \mathrm{dpi}$, NGR $\Delta \mathrm{rRNA} 1,3$ showed symbiotic efficacies similar to those of NGR234, NGR $\triangle$ rRNA1, however.

\section{Kinetics of Nodulation of Parent and rRNA-Mutant Strains on V. unguiculata}

Since deletion of one or two copies of the three rRNA operons of NGR234 did not block nodule formation or symbiotic nitrogen fixation, we examined whether kinetics of nodulation was altered. To this effect, $V$. unguiculata seedlings were inoculated with either NGR234, NGR $\Delta \mathrm{rRNA1}$, NGR $\Delta \mathrm{rRNA3}$, or NGR $\triangle$ rRNA1,3 strains and parameters such as the average $\mathrm{NN}, \mathrm{NFW}$, and SDW for 12 plants per treatment were recorded at 12,24 , and 36 days post-inoculation (dpi). In addition, the relative chlorophyll content of the first and second trifoliate leaves was monitored every third day since $12 \mathrm{dpi}$, using a SPAD chlorophyll meter. At 12 dpi all inoculated plants already carried nodules (see Figure 3A and Supplementary Figure S5). Throughout the experiment, the NGR $\triangle$ rRNA1 and NGR $\triangle$ rRNA3 mutants formed slightly fewer nodules than 
TABLE 1 | Symbiotic proficiency of NGR234, NGR $\Delta r R N A 1$, and NGR $\Delta r R N A 1,3$ on five legume species.

\begin{tabular}{|c|c|c|c|c|c|}
\hline Host & Inoculum & Plants & $\mathrm{mNN}$ & mNFW (mg) & mSDW (mg) \\
\hline \multirow[t]{4}{*}{ C. cajan (42 dpi) } & NGR234 & 12 & $25.1( \pm 6.7)$ & $839.9( \pm 202.0)$ & $1428.9( \pm 240.6)$ \\
\hline & NGR $\Delta r R N A 1$ & 12 & $24.3( \pm 6.6)$ & $879.1( \pm 92.6)$ & $1595.8( \pm 250.6)$ \\
\hline & NGR $\Delta r R N A 1,3$ & 12 & $20.4( \pm 5.2)$ & $658.7( \pm 182.6)^{*}$ & $1181.3( \pm 223.0)^{*}$ \\
\hline & Non-inoculated & 8 & 0.0 & 0.0 & $100.5( \pm 22.2)$ \\
\hline \multirow[t]{4}{*}{ M. atropurpureum (42 dpi) } & NGR234 & 10 & $60.6( \pm 12.6)$ & $487.0( \pm 151.9)$ & $783.6( \pm 182.3)$ \\
\hline & NGR $\Delta \mathrm{rRNA} 1$ & 10 & $65.6( \pm 15.4)$ & $498.8( \pm 87.9)$ & $725.1( \pm 175.4)$ \\
\hline & NGR $\Delta r R N A 1,3$ & 12 & $49.3( \pm 11.2)^{*}$ & $431.7( \pm 159.1)$ & $514.5( \pm 165.1)^{*}$ \\
\hline & Non-inoculated & 6 & 0.0 & 0.0 & $42.8( \pm 16.5)$ \\
\hline \multirow[t]{4}{*}{ L. leucocephala (49 dpi) } & NGR234 & 11 & $20.9( \pm 5.1)$ & $168.0( \pm 38.4)$ & $400.1( \pm 76.4)$ \\
\hline & $\mathrm{NGR} \Delta \mathrm{rRNA} 1$ & 11 & $20.4( \pm 5.1)$ & $164.6( \pm 34.5)$ & $399.2( \pm 89.8)$ \\
\hline & NGR $\Delta r R N A 1,3$ & 12 & $25.3( \pm 7.4)$ & $148.4( \pm 28.8)$ & $429.8( \pm 56.9)$ \\
\hline & Non-inoculated & 6 & 0.0 & 0.0 & $129.8( \pm 29.8)$ \\
\hline \multirow[t]{3}{*}{ L. leucocephala (70 dpi) } & NGR234 & 12 & $40.4( \pm 11.1)$ & $335.2( \pm 97.5)$ & $647.6( \pm 136.1)$ \\
\hline & NGR $\Delta r R N A 1,3$ & 14 & $43.7( \pm 11.3)$ & $489.3( \pm 150.2)^{*}$ & $1,001.1( \pm 290.5)^{*}$ \\
\hline & Non-inoculated & 6 & 0.0 & 0.0 & $102.2( \pm 29.5)$ \\
\hline \multirow[t]{4}{*}{ T. vogelii (42 dpi) } & NGR234 & 10 & $17.0( \pm 6.6)$ & $596.0( \pm 171)$ & $689.6( \pm 168.9)$ \\
\hline & NGR $\Delta r R N A 1$ & 11 & $16.0( \pm 5.5)$ & $587.7( \pm 159.2)$ & $683.0( \pm 175.5)$ \\
\hline & NGR $\Delta r R N A 1,3$ & 11 & $7.5( \pm 3.9)^{*}$ & $432.2( \pm 103.9)^{*}$ & $581.4( \pm 132.0)$ \\
\hline & Non-inoculated & 8 & 0.0 & 0.0 & $136.5( \pm 34.2)$ \\
\hline \multirow[t]{4}{*}{ V. unguiculata (36 dpi) } & NGR234 & 10 & $111.0( \pm 26.8)$ & $978.7( \pm 171.5)$ & $1978.8( \pm 390.2)$ \\
\hline & NGR $\Delta r R N A 1$ & 11 & $89.4( \pm 13.5)^{*}$ & $893.4( \pm 224)$ & $1730.4( \pm 369.7)$ \\
\hline & NGR $\Delta r R N A 1,3$ & 10 & $103.1( \pm 21.1)$ & $646.7( \pm 99.5)^{*}$ & $1273.5( \pm 261.1)^{*}$ \\
\hline & Non-inoculated & 4 & 0.0 & 0.0 & $193.3( \pm 79.4)$ \\
\hline
\end{tabular}

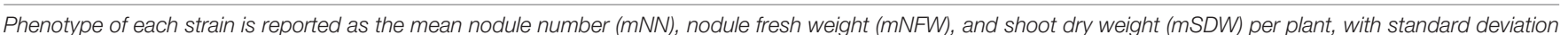

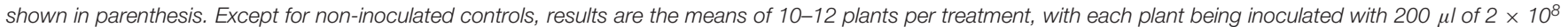

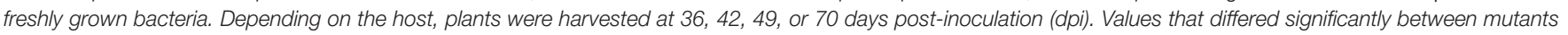
and parent NGR234 (level $\alpha=5 \%$ ) are marked with an asterisk.

NGR234, yet SDW of plants was similar indicating that symbiotic nitrogen fixation was not significantly impaired by deletion of a single rRNA operon (Figure 3C). Symbiotic proficiency of the NGR $\Delta$ rRNA1 and NGR $\Delta$ rRNA3 mutants at nearly wild type levels was also confirmed by SPAD readings, as relative chlorophyll contents of plants inoculated with NGR234 or mutants deleted of one rRNA operon were similar at all time points (Figure 3D). By contrast, at 12, 24, and $36 \mathrm{dpi}$ the number of nodules formed by NGR $\Delta$ rRNA1,3 (respectively, of $6.3,25.0$, and 76.8 nodules) was considerably reduced as compared to NGR234 (19.7, 36.4, and 102.3 nodules), suggesting nodule formation was significantly delayed (Figure 3A). Overall symbiotic activity of NGR $\Delta$ rRNA1,3 was clearly impaired as shown in Figures $3 \mathrm{C}, \mathrm{D}$, with SPAD readings of inoculated plants that plateaued at 47.9 at 33 dpi whereas those inoculated with NGR234, NGR $\Delta$ rRNA1, or NGR $\Delta$ rRNA3 mutants reached higher values comprised between 52.2 and 52.8 (Figure 3D). To check for leghemoglobin expression, several nodules formed at 12, 24, and $36 \mathrm{dpi}$ were sectioned and photographed. At $12 \mathrm{dpi}$, nodules formed by NGR234, NGR $\Delta$ rRNA1, and NGR $\triangle$ rRNA3 already contained leghemoglobin whereas most of the fewer nodules formed by NGR $\Delta$ rRNA1,3 were still white or faintly pink (see Supplementary Figure S5). At 24 dpi, all of the nodules elicited by NGR $\Delta$ rRNA1,3 had turned pink, indicating nitrogen fixation had started as confirmed by the increased SPAD values. At $36 \mathrm{dpi}$ and regardless of the inoculum, nodules formed by all mutant or parent strains expressed leghemoglobins.

\section{Competition for Nodule Occupancy by NGR234 and rRNA-Deleted Strains}

To determine whether deletion of rRNA operons influenced the competitiveness of NGR234 to form and occupy nodules, seedlings of $V$. unguiculata were inoculated with $10^{6}$ cells of NGR234 and NGR $\triangle$ rRNA1 at respective ratios of ca. 1:1, 1:4, and $4: 1$. At $24 \mathrm{dpi}$, all nodules found on roots of inoculated plants were collected and bacteria isolated from $>180$ nodules per treatment. Isolated nodule bacteria were then tested for their resistance to kanamycin and/or rifampicin, to differentiate between the NGR $\Delta$ rRNA1 $\left(\mathrm{Km}^{\mathrm{R}}\right.$ and Rif $\left.{ }^{\mathrm{R}}\right)$ and NGR234 (Rif $\left.{ }^{\mathrm{R}}\right)$ strains. Proportion of wild type versus mutant in each of the inocula was verified at the time of inoculating plants, showing that number of NGR $\Delta$ rRNA1 cells was always slightly in excess when compared to NGR234 (see Table 2). Yet, regardless of the cell ratios that were inoculated, the most abundant strain always colonized nodules more efficiently, suggesting that deletion of the rRNA1 copy had no significant effect on the ability of NGR234 to nodulate $V$. unguiculata. However, when a similar experiment was conducted using NGR234 and NGR $\Delta$ rRNA1,3 as competitors, the parent strain clearly outcompeted NGR $\Delta$ rRNA1,3 on cowpea. Given the similar symbiotic proficiencies of NGR234 and rRNA-deletion 

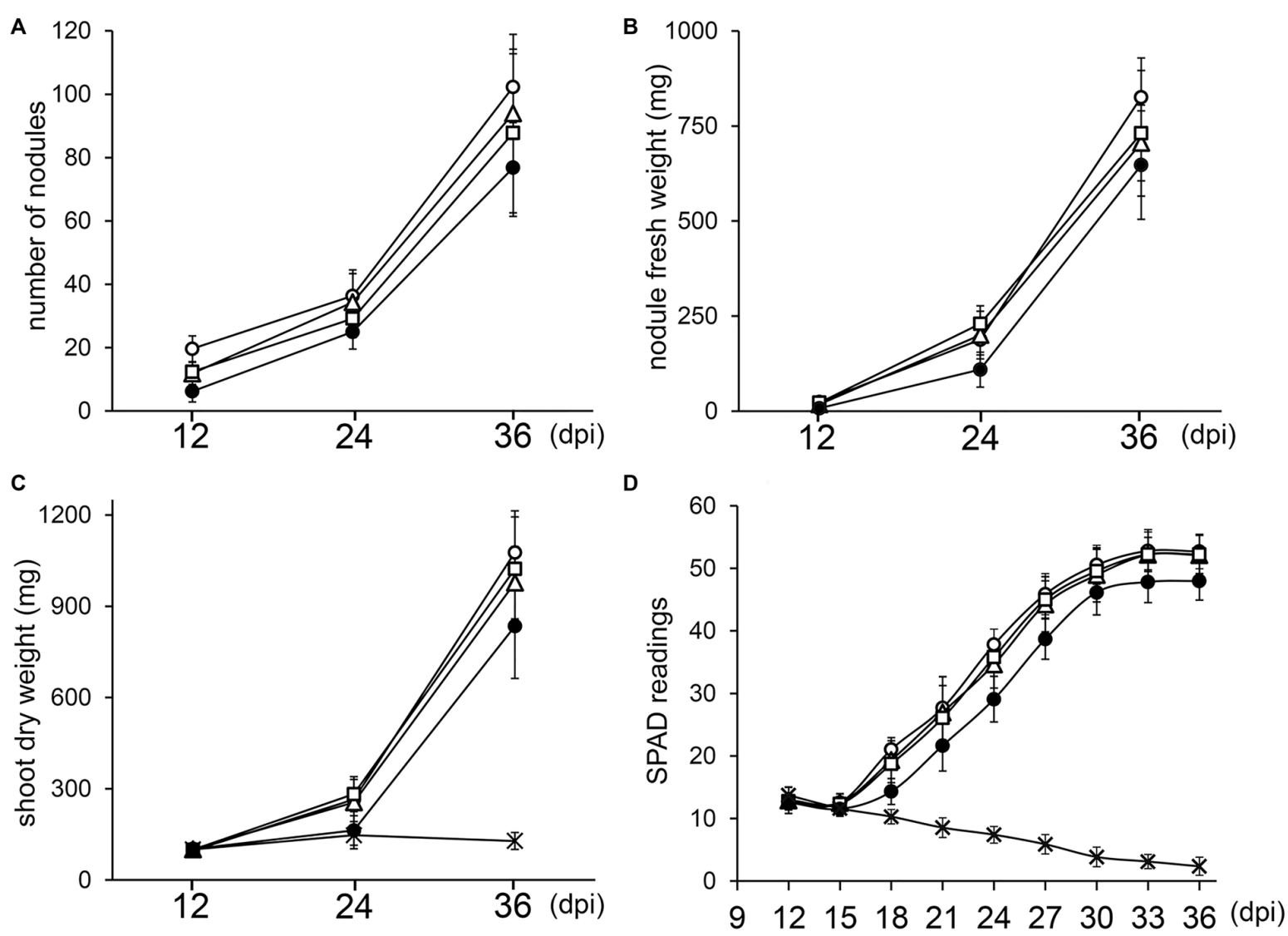

FIGURE 3 | Kinetics of nodulation for NGR234 and rRNA-deletion mutants. Plants of $V$. unguiculata were harvested at 12, 24, and 36 days post-inoculation (dpi). For each time point, the nodule number (A), nodule fresh weight (B), and shoot dry weight (C) was averaged for 10-12 plants inoculated with either NGR234 (O), NGR $\Delta$ rRNA1 $(\Delta)$, NGR $\Delta$ rRNA3 $(\square)$, and NGR $\Delta$ rRNA1,3 $(\bullet)$ strains. For non-inoculated control plants $(X)$ that did not carry nodules, only the SDW and SPAD values are shown. Relative chlorophyll contents that are expressed as mean SPAD values for eight plants per treatment (D), were measured every 3 days, starting at 12 dpi. Standard deviations are shown as bars above and below each data point.

TABLE 2 | Competition of NGR234 and rRNA-deletion mutants for nodulation of $V$. unguiculata and L. leucocephala.

\begin{tabular}{|c|c|c|c|c|c|c|}
\hline \multirow[b]{2}{*}{ Competing strains } & \multicolumn{2}{|c|}{ Inoculated cell ratios } & \multirow[b]{2}{*}{ Host plant } & \multicolumn{3}{|c|}{ Growing nodule isolates } \\
\hline & Aimed & Real & & Total & $\mathrm{Km}^{\mathrm{R}}$ & $\% \mathrm{Km}^{\mathrm{R}}$ \\
\hline & $4: 1$ & $70: 30$ & V. unguiculata & 241 & 54 & 22.4 \\
\hline & $1: 4$ & $14: 86$ & & 235 & 208 & 88.5 \\
\hline
\end{tabular}

To compare NGR234, NGRArRNA1, and NGRArRNA1,3 nodulation competitiveness, plants were challenged with mixed inoculants. On V. unguiculata, NGR234 and NGR $\triangle$ rRNA1 were inoculated at ratios of 1:1, 1:4, and 4:1 for a total of $10^{6}$ cells per plant. Given its slower growth and poor competitiveness in initial tests on cowpea, the NGR $\triangle r R N A 1,3$ mutant was inoculated at equal numbers with NGR234. For each inoculum, strain ratio was verified by plating serial dilutions of the inoculum onto TYA plates containing rifampicin or kanamycin, with kanamycin resistant $\left(\mathrm{Km}^{R}\right)$ colonies or nodule isolates scored as being or containing mutant strains. For these analyses, nodules were collected on a minimum of 10 plants per treatment and at 24 and $28 \mathrm{dpi}$ for $\mathrm{V}$. unguiculata and L. leucocephala, respectively.

mutants observed 49 dpi on L. leucocephala (Table 1), seedlings were inoculated with NGR234, NGR $\triangle$ rRNA1,3 or a $1: 1$ mixed inoculant of NGR234 and NGR $\Delta$ rRNA1,3. At $28 \mathrm{dpi}$, L. leucocephala plants challenged with the mixed inoculum were harvested and identity of nodule bacteria determined.
As shown in Table 2, NGR $\triangle$ rRNA1,3 occupied nearly half of the nodules collected at $28 \mathrm{dpi}$ indicating the mutant was apparently as competitive as the wild type for infecting L. leucocephala nodules. Interestingly, when plants treated with single-strain inoculants were harvested at $70 \mathrm{dpi}$, the dry mass 
of L. leucocephala shoots inoculated with NGR $\Delta \mathrm{rRNA} 1,3$ was in average significantly higher than when NGR234 was used as inoculum (Table 1). These results confirmed that the effect on symbiosis of deleting rRNA operons of NGR234 varied considerably between host plants.

\section{DISCUSSION}

Previous studies have addressed the impact of modifying the number or sequence of rRNA operons on various cell processes such as response of Synechococcus cyanobacteria to temperature changes (Monshupanee et al., 2006), resistance to clarithromycin and spectinomycin in Mycobacterium smegmatis (Sander et al., 1996), relative fitness and competition in E. coli batch and chemostat cultures (Stevenson and Schmidt, 2004), E. coli cell morphology (Asai et al., 1999) or sporulation of B. subtilis (Yano et al., 2013). To our knowledge, this is the first attempt at testing the effect of deleting rRNA operons on the growth and symbiotic behavior of rhizobia. NGR234 carries three functional rRNA operons that, unlike previously reported in Schmeisser et al. (2009), include identical copies of 16S rRNA genes (NGR_c26520, NGR_c30306, and NGR_c34210). Genuine polymorphisms between NGR234 rRNA operons were confirmed for the promoter and terminator regions, with the rRNA3 copy differing most from consensus, however. According to published genome sequences deposited in GenBank, intragenomic heterogeneity in rRNA operons also exists in several S. fredii strains including HH103 (NC_016812), USDA257 (NC_018000), and CCBAU 25509 (GCA_000264885 assembly). In fact, amongst the $7 \mathrm{~S}$. fredii genomes archived in GenBank as complete replicons (strains CCBAU 25509, CCBAU 45436, CCBAU 83666, NGR234, and NXT3) or as high quality permanent drafts (strains HH103 and USDA 257), only CCBAU 25509 was found to carry a 16S rRNA gene that differed by one mismatch from the other two copies. By contrast variations between allelic 5S rRNA and tRNA $^{\text {Met }}$ intergenic sequences appear to be more frequent, since S. fredii strains CCBAU 25509 and NXT3 (NZ_CP024307) also include polymorphic positions in one of the three corresponding regions of these genomes. With 4 deletions of up to 59 nucleotides and 79 additional mismatches that were all confirmed by cosmid sequencing, the $5 \mathrm{~S}$ and tRNA ${ }^{\text {Met }}$ intergenic region of the NGR234 rRNA3 operon is strikingly divergent from the other two copies (see Supplementary Figure S2). In fact, probing of the Rhizobiaceae sequences archived in GenBank (in October 2018) showed the $448 \mathrm{bp}$ long sequence between the $5^{\prime}$-end of 5S rRNA3 (NGR_c30320) to the $3^{\prime}$-end of the tRNA ${ }^{\text {Met4 }}$ (NGR_c30310) better matched sequences of Ensifer adhaerens strains OV14 (CP007236) and Casida A (on plasmid pCasidaAB; CP015882) than those of the rRNA1 and rRNA2 operons of NGR234. Whether this $5 S$ and tRNA ${ }^{\text {Met }}$ intergenic region of the NGR234 rRNA3 operon is an example of a convergent sequence evolution in distinct species of plant-interacting bacteria or results from a fusion of chromosome segments belonging to distinct strains is unknown, however.
To minimize any detrimental effect of altered stoichiometry in $5 \mathrm{~S}, 16 \mathrm{~S}$, and $23 \mathrm{~S}$ rRNA molecules on the assembly and functioning of ribosomes, mutants of NGR234 were deleted for whole rRNA1 and/or rRNA3 operons including for the corresponding promoter and terminator regions. As the Omega interposon is flanked by strong transcription terminators (Fellay et al., 1987; Fumeaux et al., 2011), polar effects on genes/operons immediately upstream and downstream of the inserted Omega cassette(s) are unlikely. Removal of entire rRNA operons also resulted in deleting copies of the tRNA ${ }^{\text {Ile }}$, tRNA Ala , and tRNA $^{f M e t}$ genes embedded within these transcription units, however. The genome of NGR234 was initially predicted to code for a set of 53 tRNAs, including a tRNA ${ }^{\text {Met }}$ copy (NGR_a03100) carried by the symbiotic plasmid pNGR234a (Schmeisser et al., 2009). NGR_a03100 was predicted in a region of pNGR234a that was found to be transcribed in free-living and endosymbiotic bacteria (Bakkou, 2011), and to be conserved in the symbiotic plasmids of strains $S$. fredii CCBAU 25509 (pSF25509a), CCBAU 45436 (pSF45436a), CCBAU 83666 (pSF83666a), HH103 (pSfHH103d), and USDA257 (pUSDA257) as well as in strains Ensifer sojae CCBAU 05684 (pSJ05684a) and Sinorhizobium sp. CCBAU 05631 (pSS05631a). GtRNAdb currently lists a total of 54 tRNAs for NGR234, with an additional tRNA $^{\text {Ser }}$ (for TCG codon) on the minus strand of positions $3,328,552-3,328,463$ of the chromosome and in place of the NGR_c31650 protein-coding gene, however (Chan and Lowe, 2016). According to GtRNAdb, the NGR234 chromosome codes for a single tRNA ${ }^{\text {Met }}$ (NGR_c27530) whereas NGR_c22590 and NGR_a03100 products, which were initially also annotated as tRNA $^{\text {Met }}$, are now predicted to be modified by a tRNA ${ }^{\text {Ile }}$-lysidine synthetase and converted into AUA codon-specific tRNAs for isoleucine (Soma et al., 2003). Thus, derivative strains of NGR234 deleted for rRNA operons will also have fewer isoleucine and alanine tRNAs for AUC and GCA codons, respectively.

Nonetheless mutants of NGR234 carrying two or only one rRNA operons were viable. Deletion of a single rRNA operon had little effect on the growth of mutants, with generation times of 25-30 min longer than for the parent NGR234 strain (ca. 2h40). This suggests NGR $\triangle$ rRNA1 and NGR $\Delta$ rRNA3 possibly compensated for deletion of one rRNA operon by an increased expression of the remaining intact copies as was reported to occur in E. coli (Condon et al., 1993). Slower growth of NGR $\Delta$ rRNA1 and NGR $\triangle$ rRNA3 was also noticeable on solid media, suggesting both mutants may eventually colonize root systems of host plants less rapidly than parent strain. With only a single rRNA operon left, NGR $\triangle$ rRNA1,3 showed a more pronounced growth defect, however. Such a difference in growth between the NGR $\triangle \mathrm{rRNA} 1$ and NGR $\Delta \mathrm{rRNA} 1,3$ mutants confirmed that, in spite of the intragenomic heterogeneity of promoter and terminator sequences discussed above, the rRNA3 operon is expressed and contributes substantially to cell metabolism. In the cyanobacterium Synechococcus strain PCC 7942, which chromosome encodes two rRNA operons (called $r r n A$ and $r r n B$ ), deletion analyses suggested $r r n A$ synthesized more rRNA and tRNA molecules than $r r n B$ (Monshupanee et al., 2006). Whether all rRNA operons of NGR234 contribute equally to rRNA and tRNA pools is unknown, but our results confirmed all three 
copies are active and contribute to cell growth. Thus, a reduction in the number of rRNA operons resulted in a concomitant slower growth of NGR234, regardless of whether bacteria were in/on rich or poor medium. This observation is consistent with previous reports of slower growth following multiple deletions of rRNA operons in E. coli, B. subtilis, or Synechococcus (Asai et al., 1999; Monshupanee et al., 2006; Yano et al., 2013; Gyorfy et al., 2015).

Deletion of a single rRNA operon had little impact on the symbiotic proficiency of NGR234 on five different legume species, with NGR $\Delta$ rRNA1 forming as many nodules as the parent strain. Nitrogen fixation was not impaired either since shoot dry weight of plants inoculated with NGR234 or NGR $\triangle$ rRNA1 was similar and SPAD values showed $V$. unguiculata plants did not suffer from nitrogen starvation once nodules were formed and fully active, and as soon as 18 dpi. By contrast, deletion of both rRNA1 and rRNA3 operons significantly impaired but did not abolish proficiency of NGR $\Delta$ rRNA1,3 on several hosts. The symbiotic defect of NGR $\Delta$ rRNA1,3 was more pronounced on $M$. atropurpureum and $V$. unguiculata with a $>30 \%$ decrease in SDW, whereas C. cajan and T. vogelii plants only suffered a ca. $15 \%$ decrease in SDW. Surprisingly, when plants were harvested 10 weeks post inoculation NGR $\triangle$ rRNA1,3 was found to be more proficient than NGR234 on L. leucocephala, thus confirming that the impact on symbiosis of deleting rRNA operons is host-specific. $M$. atropurpureum and $V$. unguiculata form $\mathrm{DN}$ within which the intracellular rhizobia undergo multiple rounds of division inside plant cells that are themselves dividing. Once cell divisions eventually stop, mature nodules with fully differentiated bacteroids are formed (Ferguson et al., 2010). By contrast, IDN of L. leucocephala possess a persistent apical meristem and bacteria that are released from infection threads into plant cells that have stopped dividing will only divide a few times before differentiating into nitrogen-fixing bacteroids (Oke and Long, 1999). Recently, IDN of Indigofera and Tephrosia species were reclassified as DN that develop from the outermost root cortical cells and have, instead of persistent meristems, secondary clusters of dividing nodule cells some of which contain infection threads (Ren, 2018). Whether the differences in the infection process and ontogeny of determinate versus indeterminate nodules may explain the distinct symbiotic phenotypes of NGR $\Delta$ rRNA1,3 on $V$. unguiculata and L. leucocephala remains to be explored.

Differentiation of rhizobia into bacteroids was reported to correlate with a reduction in translation machinery and an overall slowdown of bacteroid metabolism (Barnett et al., 2004; Becker et al., 2004). These studies were carried out on S. meliloti strain 1021, a symbiont of alfalfa that undergoes a strong endoreduplication process once released into nodule cells (Mergaert et al., 2006). Yet, a slower metabolism focused on symbiotic nitrogen fixation is most probably a feature characteristic of bacteroids in many legume hosts, in addition to auxotrophy for several amino acids and dependence for homocitrate and dicarboxylic acids provided by plants (Udvardi and Poole, 2013). Once rhizobia are established within nodule cells and have ceased to divide, transcription and translation seem to primarily target functions required for nitrogen fixation (Capela et al., 2006; Karunakaran et al., 2009), hence transforming bacteroids into nitrogen-fixing organelle-like entities. That NGR234, NGR $\Delta$ rRNA1 and NGR $\Delta$ rRNA3 share similar symbiotic phenotypes suggests mutants carrying two out of three rRNA operons can successfully meet the requirements for nitrogen fixation inside many hosts. With the loss of two out of three rRNA operons, nodulation became impaired on several legume species as shown by the significantly lower number of nodules formed by NGR $\Delta$ rRNA1,3 on C. cajan, M. atropurpureum, and T. vogelii (Table 1) and the leghemoglobin-free nodules observed at $12 \mathrm{dpi}$ on roots of V. unguiculata. Nonetheless, SPAD measurements showed that V. unguiculata plants inoculated with NGR $\Delta$ rRNA1,3 already benefited from symbiosis as early as $18 \mathrm{dpi}$ (Figure 3D). This beneficial input of NGR $\Delta$ rRNA1,3 bacteroids was insufficient to translate into a stronger shoot growth, as SDW of inoculated and non-inoculated control plants remained similar at $24 \mathrm{dpi}$, however (Figure 3C). At $30 \mathrm{dpi}$ and later, SPAD values measured for plants inoculated with NGR $\Delta$ rRNA1,3 plateaued toward the maximum of ca. 48 units, and never reached the higher values of up to 52 units that were measured for plants inoculated with NGR234, NGR $\Delta$ rRNA1 and NGR $\Delta$ rRNA3. Thus, several factors seem to contribute to the lower proficiency of NGR $\triangle$ rRNA1,3 on cowpea: a delay in nodule formation and in the establishment of fixing nodules, as well as a reduced capacity of the NGR $\Delta$ rRNA1,3-infected nodules to sustain plant development over a longer period. Yet, the NGR $\Delta$ rRNA1,3 and $L$. leucocephala association appeared as fully functional (Table 1), indicating the minimal requirements for symbiosis and dynamics of nodulation and nitrogen fixation must differ considerably between legume species. Whether L. leucocephala uses yet unknown compensation mechanisms to suppress the NGR $\triangle$ rRNA1,3 deficiencies, allows a greater colonization of nodule cells by the mutant or is globally a less-demanding host for rhizobia capable of nodulation remains to be elucidated.

Many factors contribute to make rhizobia competitive for nodulation. For examples production of rhizobitoxine by Bradyrhizobium elkanii USDA94 strain enhances its competitive nodulation on $M$. atropurpureum (Okazaki et al., 2003). Utilization of several carbon sources has been shown to be important for competing for nodule occupancy in R. leguminosarum and S. meliloti (Fry et al., 2001; Kohler et al., 2010; Ding et al., 2012); Cell surface components such as exo- or lipo-polysaccharides contribute to $S$. meliloti ability to compete for nodule occupancy (Lagares et al., 1992; Geddes et al., 2014); General stress response (GSR) resulting in the induction of protection or damage repair functions in $B$. diazoefficiens $110^{\mathrm{T}}$ are crucial for synchronization of infection thread formation, colonization, and nodule development (Ledermann et al., 2018); and presence of non-symbiotic bacteria such as Acinetobacter spp., Enterobacter aerogenes, Klebsiella pneumoniae, and Pseudomonas marginalis reduced alfalfa nodulation by S. meliloti (Li and Alexander, 1986). Deletion of a single rRNA operon, which slightly slowed growth and made mutants enter stationary phase earlier (see Figure 2) did not impair NGR $\Delta$ rRNA1 competitiveness for nodulation on $V$. unguiculata. In fact, NGR $\Delta$ rRNA1 occupied more nodules than NGR234 (71\% versus $29 \%)$ when both strains were co-inoculated at 
roughly similar titers. Furthermore, while the slower dividing NGR $\Delta$ rRNA1,3 occupied only $4 \%$ of $V$. unguiculata nodules, it successfully infected half of $L$. leucocephala nodules when co-inoculated with the parent at nearly 1:1 ratio. Thus, slower growth is not necessarily detrimental to competition for nodulation, as shown in a different context by the ability of a slow-growing Bradyrhizobium strain E109 to outcompete the fast-growing E. fredii strain SMH12 on soybean (Pastorino et al., 2015). Given that NGR234 and derivative mutants share otherwise identical repertoires of housekeeping and symbiotic genes, we expected the deletion of two out of three rRNA operons to considerably affect the fitness of NGR $\Delta$ rRNA1,3 with possibly pleiotropic effects on cell division, metabolism and motility, and as a consequence on symbiotic proficiency. Yet, NGR $\Delta$ rRNA1,3 performed surprisingly well as a single inoculum on all of the five legume species tested so far, and in particular on L. leucocephala where it showed improved proficiency when compared to NGR234. Together these results highlight the apparent robustness of symbiotic nitrogen fixation, but also how certain legume hosts can accommodate bacteroid deficiencies, as was recently illustrated by the unusual phenotype of the NGR $\Delta$ nifQ mutant on several species (Saad et al., 2018).

\section{REFERENCES}

Acinas, S. G., Marcelino, L. A., Klepac-Ceraj, V., and Polz, M. F. (2004). Divergence and redundancy of $16 \mathrm{~S}$ rRNA sequences in genomes with multiple rrn operons. J. Bacteriol. 186, 2629-2635. doi: 10.1128/Jb.186.9.2629-2635.2004

Amadou, C., Pascal, G., Mangenot, S., Glew, M., Bontemps, C., Capela, D., et al. (2008). Genome sequence of the $\beta$-rhizobium Cupriavidus taiwanensis and comparative genomics of rhizobia. Genome Res. 18, 1472-1483. doi: 10.1101/ gr.076448.108

Asai, T., Condon, C., Voulgaris, J., Zaporojets, D., Shen, B. H., Al-Omar, M., et al. (1999). Construction and initial characterization of Escherichia coli strains with few or no intact chromosomal rRNA operons. J. Bacteriol. 181, 3803-3809.

Bakkou, N. (2011). Characterization of the Endosymbiotic forms of Sinorhizobium sp. Strain NGR234. Ph.D. thesis, University of Geneva, Geneva, 4286.

Barnett, M. J., Toman, C. J., Fisher, R. F., and Long, S. R. (2004). A dual-genome symbiosis chip for coordinate study of signal exchange and development in a prokaryote-host interaction. Proc. Natl. Acad. Sci. U.S.A. 101, 16636-16641. doi: 10.1073/pnas.0407269101

Becker, A., Berges, H., Krol, E., Bruand, C., Ruberg, S., Capela, D., et al. (2004). Global changes in gene expression in Sinorhizobium meliloti 1021 under microoxic and symbiotic conditions. Mol. Plant Microbe Interact. 17, 292-303. doi: 10.1094/MPMI.2004.17.3.292

Berg, K. L., Squires, C., and Squires, C. L. (1989). Ribosomal-RNA operon antitermination. Function of leader and spacer region box-B box-A sequences and their conservation in diverse microorganisms. J. Mol. Biol. 209, 345-358. doi: 10.1016/0022-2836(89)90002-8

Beringer, J. E. (1974). R factor transfer in Rhizobium leguminosarum. J. Gen. Microbiol. 84, 188-198. doi: 10.1099/00221287-84-1-188

Bollenbach, T., Quan, S., Chait, R., and Kishony, R. (2009). Nonoptimal microbial response to antibiotics underlies suppressive drug interactions. Cell 139, 707-718. doi: 10.1016/j.cell.2009.10.025

Broughton, W. J., and Dilworth, M. J. (1971). Control of leghaemoglobin synthesis in snake beans. Biochem. J. 125, 1075-1080. doi: 10.1042/bj1251075

Broughton, W. J., Jabbouri, S., and Perret, X. (2000). Keys to symbiotic harmony. J. Bacteriol. 182, 5641-5652. doi: 10.1128/JB.182.20.5641-5652.2000

Broughton, W. J., Wong, C.-H., Lewin, A., Samrey, U., Myint, H., Meyer, z. A., H., et al. (1986). Identification of Rhizobium plasmid sequences involved in recognition of Psophocarpus, Vigna, and other legumes. J. Cell Biol. 102, 1173-1182. doi: $10.1083 /$ jcb.102.4.1173

\section{AUTHOR CONTRIBUTIONS}

$\mathrm{XP}$ and AEC conceived the experiments, analyzed the data, and wrote the manuscript. AEC performed the experiments. Both authors have read and approved the final manuscript.

\section{FUNDING}

We would like to thank Natalia Giot for her help in many aspects of this work, and the University of Geneva as well as the Swiss National Science Foundation (grants 31003A-146548 and 31003A-173191) for financial support. AEC acknowledges the generous support of a Swiss Government Excellence Scholarship for foreign students.

\section{SUPPLEMENTARY MATERIAL}

The Supplementary Material for this article can be found online at: https://www.frontiersin.org/articles/10.3389/fmicb. 2019.00154/full\#supplementary-material

Capela, D., Filipe, C., Bobik, C., Batut, J., and Bruand, C. (2006). Sinorhizobium meliloti differentiation during symbiosis with alfalfa: a transcriptomic dissection. Mol. Plant Microbe Interact. 19, 363-372. doi: 10.1094/MPMI-190363

Chan, P. P., and Lowe, T. M. (2016). GtRNAdb 2.0: an expanded database of transfer RNA genes identified in complete and draft genomes. Nucleic Acids Res. 44, D184-D189. doi: 10.1093/nar/gkv1309

Coenye, T., and Vandamme, P. (2003). Intragenomic heterogeneity between multiple $16 \mathrm{~S}$ ribosomal RNA operons in sequenced bacterial genomes. FEMS Microbiol. Lett. 228, 45-49. doi: 10.1016/S0378-1097(03)00717-1

Condon, C., French, S., Squires, C., and Squires, C. L. (1993). Depletion of functional ribosomal RNA operons in Escherichia coli causes increased expression of the remaining intact copies. EMBO J. 12, 4305-4315. doi: 10.1002/ j.1460-2075.1993.tb06115.x

Ding, H., Yip, C. B., Geddes, B. A., Oresnik, I. J., and Hynes, M. F. (2012). Glycerol utilization by Rhizobium leguminosarum requires an $\mathrm{ABC}$ transporter and affects competition for nodulation. Microbiology 158, 1369-1378. doi: 10. 1099/mic.0.057281-0

Farnham, P. J., and Platt, T. (1981). Rho-independent termination: dyad symmetry in DNA causes RNA-polymerase to pause during transcription in vitro. Nucleic Acids Res. 9, 563-577. doi: 10.1093/nar/9.3.563

Fellay, R., Frey, J., and Krisch, H. (1987). Interposon mutagenesis of soil and water bacteria: a family of DNA fragments designed for in vitro insertional mutagenesis of Gram-negative bacteria. Gene 52, 147-154. doi: 10.1016/03781119(87)90041-2

Ferguson, B. J., Indrasumunar, A., Hayashi, S., Lin, M. H., Lin, Y. H., Reid, D. E., et al. (2010). Molecular analysis of legume nodule development and autoregulation. J. Integr. Plant Biol. 52, 61-76. doi: 10.1111/j.1744-7909.2010. 00899.x

Figurski, D. H., and Helinski, D. R. (1979). Replication of an origin-containing derivative of plasmid RK2 dependent on a plasmid function provided in trans. Proc. Natl. Acad. Sci. U.S.A. 76, 1648-1652. doi: 10.1073/pnas.76.4.1648

Fossou, R. K., Ziegler, D., Zézé, A., Barja, F., and Perret, X. (2016). Two major clades of bradyrhizobia dominate symbiotic interactions with pigeonpea in fields of Côte d'Ivoire. Front. Microbiol. 7:1793. doi: 10.3389/fmicb.2016.01793

Fournier, J., Teillet, A., Chabaud, M., Ivanov, S., Genre, A., Limpens, E., et al. (2015). Remodeling of the infection chamber before infection thread formation reveals a two-step mechanism for rhizobial entry into the host legume root hair. Plant Physiol. 167, 1233-1242. doi: 10.1104/pp.114.253302 
Fournier, J., Timmers, A. C. J., Sieberer, B. J., Jauneau, A., Chabaud, M., and Barker, D. G. (2008). Mechanism of infection thread elongation in root hairs of Medicago truncatula and dynamic interplay with associated rhizobial colonization. Plant Physiol. 148, 1985-1995. doi: 10.1104/pp.108.125674

Freiberg, C., Fellay, R., Bairoch, A., Broughton, W. J., Rosenthal, A., and Perret, X. (1997). Molecular basis of symbiosis between Rhizobium and legumes. Nature 387, 394-401. doi: 10.1038/387394a0

Fry, J., Wood, M., and Poole, P. S. (2001). Investigation of myo-inositol catabolism in Rhizobium leguminosarum bv. viciae and its effect on nodulation competitiveness. Mol. Plant Microbe Interact. 14, 1016-1025. doi: 10.1094/ Mpmi.2001.14.8.1016

Fumeaux, C., Bakkou, N., Kopćinska, J., Golinowski, W., Westenberg, D. J., Müller, P., et al. (2011). Functional analysis of the nifQdctA1y4vGHIJ operon of Sinorhizobium fredii strain NGR234 using a transposon with a NifA-dependent read-out promoter. Microbiology 157, 2745-2758. doi: 10.1099/mic.0.049999-0

Gage, D. J. (2002). Analysis of infection thread development using Gfp- and DsRed-expressing Sinorhizobium meliloti. J. Bacteriol. 184, 7042-7046. doi: 10. 1128/JB.184.24.7042-7046.2002

Gage, D. J. (2004). Infection and invasion of roots by symbiotic, nitrogen-fixing rhizobia during nodulation of temperate legumes. Microbiol. Mol. Biol. Rev. 68, 280-300. doi: 10.1128/MMBR.68.2.280-300.2004

Geddes, B. A., Gonzalez, J. E., and Oresnik, I. J. (2014). Exopolysaccharide production in response to medium acidification is correlated with an increase in competition for nodule occupancy. Mol. Plant Microbe Interact. 27, 1307-1317. doi: 10.1094/Mpmi-06-14-0168-R

Gyorfy, Z., Draskovits, G., Vernyik, V., Blattner, F. F., Gaal, T., and Posfai, G. (2015). Engineered ribosomal RNA operon copy-number variants of E. coli reveal the evolutionary trade-offs shaping rRNA operon number. Nucleic Acids Res. 43, 1783-1794. doi: 10.1093/nar/gkv040

Jones, K. M., Kobayashi, H., Davies, B. W., Taga, M. E., and Walker, G. C. (2007). How rhizobial symbionts invade plants: the Sinorhizobium-Medicago model. Nat. Rev. Microbiol. 5, 619-633. doi: 10.1038/nrmicro1705

Karunakaran, R., Ramachandran, V. K., Seaman, J. C., East, A. K., Mouhsine, B., Mauchline, T. H., et al. (2009). Transcriptomic analysis of Rhizobium leguminosarum biovar viciae in symbiosis with host plants Pisum sativum and Vicia cracca. J. Bacteriol. 191, 4002-4014. doi: 10.1128/JB.00165-09

Keyser, H. H., Bohlool, B. B., Hu, T. S., and Weber, D. F. (1982). Fast-growing rhizobia isolated from root nodules of soybean. Science 215, 1631-1632. doi: $10.1126 /$ science.215.4540.1631

Kiers, E. T., Rousseau, R. A., West, S. A., and Denison, R. F. (2003). Host sanctions and the legume-rhizobium mutualism. Nature 425, 78-81. doi: 10 . 1038/nature01931

Klappenbach, J. A., Saxman, P. R., Cole, J. R., and Schmidt, T. M. (2001). rrndb: the ribosomal RNA operon copy number database. Nucleic Acids Res. 29, 181-184. doi: 10.1093/nar/29.1.181

Kohler, P. R. A., Zheng, J. Y., Schoffers, E., and Rossbach, S. (2010). Inositol catabolism, a key pathway in Sinorhizobium meliloti for competitive host nodulation. Appl. Environ. Microbiol. 76, 7972-7980. doi: 10.1128/Aem. 01972-10

Lagares, A., Caetanoanolles, G., Niehaus, K., Lorenzen, J., Ljunggren, H. D., Puhler, A., et al. (1992). A Rhizobium meliloti lipopolysaccharide mutant altered in competitiveness for nodulation of Alfalfa. J. Bacteriol. 174, 5941-5952. doi: $10.1128 / \mathrm{jb}$.174.18.5941-5952.1992

Ledermann, R., Bartsch, I., Müller, B., Wülser, J., and Fischer, H. M. (2018). A functional general stress response of Bradyrhizobium diazoefficiens is required for early stages of host plant infection. Mol. Plant Microbe Interact. 31, 537-547. doi: 10.1094/Mpmi-11-17-0284-R

Lewin, A., Rosenberg, C., Meyer z. A., H., Wong, C. H., Nelson, L., Manen, J. F., et al. (1987). Multiple host-specificity loci of the broad host range Rhizobium sp. NGR234 selected using the widely compatible legume Vigna unguiculata. Plant Mol. Biol. 8, 447-459. doi: 10.1007/BF00017990

Li, D. M., and Alexander, M. (1986). Bacterial growth rates and competition affect nodulation and root colonization by Rhizobium meliloti. Appl. Environ. Microbiol. 52, 807-811.

Marchetti, M., Catrice, O., Batut, J., and Masson-Boivin, C. (2011). Cupriavidus taiwanensis bacteroids in Mimosa pudica indeterminate nodules are not terminally differentiated. Appl. Environ. Microb. 77, 2161-2164. doi: 10.1128/ Aem.02358-10
Markwell, J., and Blevins, D. (1999). The minolta SPAD-502 leaf chlorophyll meter: an exciting new tool for education in the plant sciences. Am. Biol. Teach. 61, 672-676. doi: 10.2307/4450800

Marx, C. J., Bringel, F., Chistoserdova, L., Moulin, L., Farhan, U., Haque, M., et al. (2012). Complete genome sequences of six strains of the genus Methylobacterium. J. Bacteriol. 194, 4746-4748. doi: 10.1128/Jb.01009-12

Masson-Boivin, C., Giraud, E., Perret, X., and Batut, J. (2009). Establishing nitrogen-fixing symbiosis with legumes: how many rhizobium recipes? Trends Microbiol. 17, 458-466. doi: 10.1016/j.tim.2009.07.004

Mergaert, P., Uchiumi, T., Alunni, B., Evanno, G., Cheron, A., Catrice, O., et al. (2006). Eukaryotic control on bacterial cell cycle and differentiation in the Rhizobium-legume symbiosis. Proc. Natl. Acad. Sci. U.S.A. 103, 5230-5235. doi: 10.1073/pnas.0600912103

Monshupanee, T., Fa-Aroonsawat, S., and Chungjatupornchai, W. (2006). A cyanobacterial strain with all chromosomal rRNA operons inactivated: a single nucleotide mutation of $23 \mathrm{~S}$ rRNA confers temperature-sensitive phenotypes. Microbiology 152, 1417-1425. doi: 10.1099/mic.0.28691-0

Montiel, J., Downie, J. A., Farkas, A., Bihari, P., Herczeg, R., Bálint, B., et al. (2017). Morphotype of bacteroids in different legumes correlates with the number and type of symbiotic NCR peptides. Proc. Natl. Acad. Sci. U.S.A. 114, 5041-5046. doi: $10.1073 /$ pnas.1704217114

Moulin, L., Klonowska, A., Caroline, B., Booth, K., Vriezen, J. A. C., Melkonian, R., et al. (2014). Complete genome sequence of Burkholderia phymatum STM815, a broad host range and efficient nitrogen-fixing symbiont of Mimosa species. Stand. Genomic Sci. 9, 763-774. doi: 10.4056/sigs.4861021

Nanamiya, H., Sato, M., Masuda, K., Sato, M., Wada, T., Suzuki, S., et al. (2010). Bacillus subtilis mutants harbouring a single copy of the rRNA operon exhibit severe defects in growth and sporulation. Microbiology 156, 2944-2952. doi: 10.1099/mic.0.035295-0

Nemergut, D. R., Knelman, J. E., Ferrenberg, S., Bilinski, T., Melbourne, B., Jiang, L., et al. (2016). Decreases in average bacterial community rRNA operon copy number during succession. ISME J. 10, 1147-1156. doi: 10.1038/ismej. 2015.191

Okazaki, S., Yuhashi, K. I., and Minamisawa, K. (2003). Quantitative and timecourse evaluation of nodulation competitiveness of rhizobitoxine-producing Bradyrhizobium elkanii. FEMS Microbiol. Ecol. 45, 155-160. doi: 10.1016/ S0168-6496(03)00132-6

Oke, V., and Long, S. R. (1999). Bacteroid formation in the Rhizobium-legume symbiosis. Curr. Opin. Microbiol. 2, 641-646. doi: 10.1016/S1369-5274(99) 00035-1

Oldroyd, G. E., Murray, J. D., Poole, P. S., and Downie, J. A. (2011). The rules of engagement in the legume-rhizobial symbiosis. Annu. Rev. Genet. 45, 119-144. doi: 10.1146/annurev-genet-110410-132549

Pastorino, G., Martinez Alcántara, V., Malbrán, I., Videira, L., Sarinelli, J., and Balatti, P. A. (2015). Ensifer (Sinorhizobium) fredii interacted more efficiently than Bradyrhizobium japonicum with soybean. J. Agric. Ecol. Res. Int. 2, 10-19. doi: 10.9734/JAERI/2015/13163

Perret, X., Broughton, W. J., and Brenner, S. (1991). Canonical ordered cosmid library of the symbiotic plasmid of Rhizobium species NGR234. Proc. Natl. Acad. Sci. U.S.A. 88, 1923-1927. doi: 10.1073/pnas.88.5.1923

Perret, X., Kobayashi, H., and Collado-Vides, J. (2003). Regulation of expression of symbiotic genes in Rhizobium sp. NGR234. Indian J. Exp. Biol. 41, 1101-1113.

Perret, X., Staehelin, C., and Broughton, W. J. (2000). Molecular basis of symbiotic promiscuity. Microbiol. Mol. Biol. Rev. 64, 180-201. doi: 10.1128/MMBR.64.1. 180-201.2000

Poole, P., Ramachandran, V., and Terpolilli, J. (2018). Rhizobia: from saprophytes to endosymbionts. Nat. Rev. Microbiol. 16, 291-303. doi: 10.1038/nrmicro. 2017.171

Prentki, P., and Krisch, H. M. (1984). In vitro insertional mutagenesis with a selectable DNA fragment. Gene 29, 303-313. doi: 10.1016/0378-1119(84) 90059-3

Pueppke, S. G., and Broughton, W. J. (1999). Rhizobium sp. strain NGR234 and $R$. fredii USDA257 share exceptionally broad, nested host ranges. Mol. Plant Microbe Interact. 12, 293-318. doi: 10.1094/MPMI.1999.12. 4.293

Quandt, J., and Hynes, M. F. (1993). Versatile suicide vectors which allow direct selection for gene replacement in Gram-negative bacteria. Gene 127, 15-21. doi: 10.1016/0378-1119(93)90611-6 
Ren, G. (2018). The Evolution of Determinate and Indeterminate Nodules Within the Papilionoideae Subfamily. Ph.D. thesis, Wageningen University, Wageningen. doi: $10.18174 / 429101$

Roller, B. R. K., Stoddard, S. F., and Schmidt, T. M. (2016). Exploiting rRNA operon copy number to investigate bacterial reproductive strategies. Nat. Microbiol. 1:16160. doi: 10.1038/Nmicrobiol.2016.160

Ross, W., Gosink, K. K., Salomon, J., Igarashi, K., Zou, C., Ishihama, A., et al. (1993). A third recognition element in bacterial promoters - DNA-binding by the alpha-subunit of RNA-polymerase. Science 262, 1407-1413. doi: 10.1126/ science. 8248780

Saad, M. M., Michalet, S., Fossou, R. K., Putnik-Delić, M., Crèvecoeur, M., Meyer, J., et al. (2018). Loss of NifQ leads to accumulation of porphyrins and altered metal-homeostasis in nitrogen-fixing symbioses. Mol. Plant Microbe Interact. doi: 10.1094/MPMI-07-18-0188-R [Epub ahead of print].

Sander, P., Prammananan, T., and Bottger, E. C. (1996). Introducing mutations into a chromosomal rRNA gene using a genetically modified eubacterial host with a single rRNA operon. Mol. Microbiol. 22, 841-848. doi: 10.1046/j.13652958.1996.01532.x

Saroso, S., Glenn, A. R., and Dilworth, M. J. (1984). Carbon utilization by freeliving and bacteroid forms of cowpea Rhizobium strain NGR234. J. Gen. Microbiol. 130, 1809-1814. doi: 10.1099/00221287-130-7-1809

Schindelin, J., Arganda-Carreras, I., Frise, E., Kaynig, V., Longair, M., Pietzsch, T., et al. (2012). Fiji: an open-source platform for biological-image analysis. Nat. Methods 9, 676-682. doi: 10.1038/nmeth.2019

Schmeisser, C., Liesegang, H., Krysciak, D., Bakkou, N., Le Quéré, A., Wollherr, A., et al. (2009). Rhizobium sp. NGR234 possesses a remarkable number of secretion systems. Appl. Environ. Microbiol. 75, 4035-4045. doi: 10.1128/AEM. 00515-09

Shrestha, P. M., Noll, M., and Liesack, W. (2007). Phylogenetic identity, growthresponse time and rRNA operon copy number of soil bacteria indicate different stages of community succession. Environ. Microbiol. 9, 2464-2474. doi: 10.1111/ j.1462-2920.2007.01364.x

Soma, A., Ikeuchi, Y., Kanemasa, S., Kobayashi, K., Ogasawara, N., Ote, T., et al. (2003). An RNA-modifying enzyme that governs both the codon and amino acid specificities of isoleucine tRNA. Mol. Cell 12, 689-698. doi: 10.1016/S10972765(03)00346-0

Sprent, J. I., Ardley, J., and James, E. K. (2017). Biogeography of nodulated legumes and their nitrogen-fixing symbionts. New Phytol. 215, 40-56. doi: 10.1111/nph. 14474

Sprent, J. I., Ardley, J. K., and James, E. K. (2013). From North to South: a latitudinal look at legume nodulation processes. S. Afr. J. Bot. 89, 31-41. doi: 10.1016/j.sajb. 2013.06.011
Srivastava, A. K., and Schlessinger, D. (1990). Mechanism and regulation of bacterial ribosomal-RNA processing. Annu. Rev. Microbiol. 44, 105-129. doi: 10.1146/annurev.mi.44.100190.000541

Stevenson, B. S., and Schmidt, T. M. (2004). Life history implications of rRNA gene copy number in Escherichia coli. Appl. Environ. Microbiol. 70, 6670-6677. doi: 10.1128/Aem.70.11.6670-6677.2004

Triplett, E. W., and Sadowsky, M. J. (1992). Genetics of competition for nodulation of legumes. Аnnu. Rev. Microbiol. 46, 399-428. doi: 10.1146/annurev.mi.46. 100192.002151

Udvardi, M., and Poole, P. S. (2013). Transport and metabolism in legume-rhizobia symbioses. Annu. Rev. Plant Biol. 64, 781-805. doi: 10.1146/annurev-arplant050312-120235

Viprey, V., Rosenthal, A., Broughton, W. J., and Perret, X. (2000). Genetic snapshots of the Rhizobium species NGR234 genome. Genome Biol. 1:research0014.1-14.17. doi: 10.1186/gb-2000-1-6-research 0014

Xiao, T. T., Schilderink, S., Moling, S., Deinum, E. E., Kondorosi, É, Franssen, H., et al. (2014). Fate map of Medicago truncatula root nodules. Development 141, 3517-3528. doi: 10.1242/dev.110775

Xu, L. M., Ge, C., Cui, Z., Li, J., and Fan, H. (1995). Bradyrhizobium liaoningense sp. nov., isolated from the root nodules of soybeans. Int. J. Syst. Bacteriol. 45, 706-711. doi: 10.1099/00207713-454-706

Yano, K., Wada, T., Suzuki, S., Tagami, K., Matsumoto, T., Shiwa, Y., et al. (2013). Multiple rRNA operons are essential for efficient cell growth and sporulation as well as outgrowth in Bacillus subtilis. Microbiology 159, 2225-2236. doi: 10.1099/mic.0.067025-0

Ziegler, D., Mariotti, A., Pflüger, V., Saad, M., Vogel, G., Tonolla, M., et al. (2012). In situ identification of plant-invasive bacteria with MALDITOF mass spectrometry. PLoS One 7:e37189. doi: 10.1371/journal.pone.003 7189

Conflict of Interest Statement: The authors declare that the research was conducted in the absence of any commercial or financial relationships that could be construed as a potential conflict of interest.

Copyright (c) 2019 Cherni and Perret. This is an open-access article distributed under the terms of the Creative Commons Attribution License (CC BY). The use, distribution or reproduction in other forums is permitted, provided the original author(s) and the copyright owner(s) are credited and that the original publication in this journal is cited, in accordance with accepted academic practice. No use, distribution or reproduction is permitted which does not comply with these terms. 